Article

\title{
Are There Thresholds in Glioblastoma Cell Death Responses Triggered by Temozolomide?
}

\author{
Yang $\mathrm{He}^{\mathbb{D}}$ and Bernd Kaina * $\mathbb{D}$ \\ Institute of Toxicology, University Medical Center, Obere Zahlbacher Str. 67, D-55131 Mainz, Germany; \\ yanghe01@uni-mainz.de \\ * Correspondence: kaina@uni-mainz.de; Tel.: +49-6131-17-9217; Fax: +49-6131-17-8499
}

Received: 15 February 2019; Accepted: 22 March 2019; Published: 28 March 2019

Abstract: Temozolomide (TMZ) is an alkylating agent used in the treatment of high-grade malignant glioma, notably glioblastoma multiforme, the most aggressive form of brain cancer. The drug induces a dozen DNA methylation adducts, including $O^{6}$-methylguanine $\left(O^{6} \mathrm{MeG}\right)$, which is the most toxic primary DNA lesion as it causes the formation of DNA double-strand breaks (DSBs) that trigger apoptosis. In p53 wild-type cells, TMZ activates p-p53ser15 and p-p53ser46, which have opposing dual functions regulating survival and death, respectively. Since the use of TMZ in a therapeutic setting is limited because of its side effects, the question arises as to the existence of threshold doses that activate the death pathway and start apoptosis. To determine whether there is a threshold for the TMZ-induced DNA damage response and exploring the factors regulating the switch between p53 dependent survival and death, the glioblastoma lines LN-229 (deficient in MGMT) and LN-229MGMT (stably transfected with MGMT) were exposed to different doses of TMZ. p53 protein expression and phosphorylation levels of p-p53ser15 and p-p53ser46 were determined by Western blotting. Also, apoptosis, senescence and autophagy levels were checked after different doses of TMZ. The results show that pro-survival p-p53ser15 and pro-death p-p53ser46 were induced by $\mathrm{O}^{6} \mathrm{MeG}$ in a specific dose- and time-dependent manner. p-p53ser15 was an early response while p-p53ser46 was activated at later times following treatment. Unexpectedly, the dose-response curves for total p53, p-p53ser15 and p-p53ser46 were linear, without an obvious threshold. $0^{6} \mathrm{MeG}$ induces apoptosis late after treatment as a linear function of TMZ dose. This was observed for both p53 proficient LN-229 and p53 lacking LN-308 cells. A linear dose-response after TMZ was also observed for senescence and autophagy as well as $\gamma \mathrm{H} 2 \mathrm{AX}$, an indicator of DSBs that are considered to be the downstream trigger of apoptosis, senescence and autophagy. LN-229MGMT cells were highly resistant to all measured endpoints because of repair of the critical primary lesion. Although LN-308 were less responsive than LN-229 to TMZ, they displayed the same TMZ-induced DSB level. The observed linear dose-responses are not compatible with the view that low DNA damage level evokes survival while high damage level activates death functions. The data bear important therapeutic implications as they indicate that even low doses of TMZ may elicit a cytotoxic response. However, since $O^{6} \mathrm{MeG}$ triggers apoptosis, senescence and autophagy in the same dose range, it is likely that the accumulation of senescent cells in the population counteracts the killing effect of the anticancer drug.

Keywords: DNA damage; O6-alkylguanine; temozolomide; dose-response curves; time-response; glioblastoma; glioma; apoptosis; autophagy; senescence; p53

\section{Introduction}

In cancer therapy, chemotherapeutics with genotoxic activity are being used routinely. It is well known that these anticancer drugs induce DNA damage that triggers complex cellular DNA damage responses (DDR), which determine the fate of the cell, making the decision between 
survival and death [1]. Key players involved in this scenario are the DDR kinases ATM, ATR and DNA-PK, the checkpoint kinases CHK1, CHK2, the stress kinase HIPK2, and further downstream, the transcription factor and tumor suppressor protein p53. During activation, p53 becomes phosphorylated, liberates from its inhibitor MDM1, becomes stabilized and binds as a transcription factor in a dimeric form to a p53 consensus sequence in the promoter of pro- and anti-apoptotic genes [2]. In addition, p53 has other functions that are independent of transcriptional activation of genes [3]. It is generally believed that low DNA damage levels activate pro-survival and high damage levels activate pro-death genes and cellular functions [4-6]. For example, p53 stimulates the transcription of p21, which results in cell cycle arrest, and DNA repair genes such as DDB2, which enhances the repair capacity, leading to removal of toxic DNA lesions from DNA [7]. At high dose levels p53 turns into a "killer" through activation of pro-death functions such as the proapoptotic genes Bax, Bak and Fas [2]. Although this concept derived mostly from work with ionizing radiation is reasonable, there is not much experimental proof of it for chemical genotoxins, notably anticancer drugs. The concept implicates that there are threshold doses for cell death, i.e., low doses do not elicit activation of apoptosis pathways while high doses do.

A proof of this concept requires maximum understanding of the cell death pathways activated by a given genotoxicant. A well-studied drug in this respect is temozolomide (TMZ), which is used in first-line therapy for high-grade gliomas, including astrocytoma ( $\mathrm{WHO}^{0} 3$ ) and glioblastoma multiforme (glioma $\mathrm{WHO}^{0} 4$ ) [8]. The main target of TMZ is the nuclear DNA in which, similar to other $\mathrm{S}_{\mathrm{N}} 1$ alkylating agents, at least 12 nucleophilic sites can become methylated [9]. The major methylation products are $\mathrm{N}$-methylpurines such as N7-methylguanine, N3-methylguanine and N3-methyladenine, while $O$-methylpurines are less frequent. Thus, $O^{6}$-methylguanine $\left(O^{6} \mathrm{MeG}\right)$ accounts for maximally $7 \%$ of the total methylations [9]. Although produced in minor amounts, the damage is highly genotoxic and cytotoxic if not repaired by the suicide enzyme $O^{6}$-methylguanine-DNA methyltransferase (MGMT) [10]. If cells are repair competent, $\mathrm{O}^{6} \mathrm{MeG}$ is quickly removed from DNA. Under this condition, cells become highly resistant to $O^{6}$-alkylating agents and higher doses of a methylating agent are required to achieve a killing effect, which results from saturation of base excision repair and repair by ALKB homologous proteins (ALKBH) [11]. Therefore, in the high dose setting, other lesions than $O^{6} \mathrm{MeG}$, which are less toxic, give rise to cell death. The doses of TMZ in a therapeutic setting are very likely too low to achieve cell death resulting from non-repaired $\mathrm{N}$-alkylations. Therefore, with an achievable serum concentration of up to $50 \mu \mathrm{M} \mathrm{TMZ}$, the $O^{6} \mathrm{MeG}$ response plays a key role in determining tumor cell death.

The mechanisms of $O^{6} \mathrm{MeG}$ triggered genotoxic responses have been described previously [11]. In brief, $\mathrm{O}^{6} \mathrm{MeG}$ is a mutagenic mispairing lesion that results in mismatches with thymine that are subject to mismatch repair (MMR). Reinsertion of thymine during MMR causes a futile MMR cycle with gapped DNA that finally gives rise to DNA replication blockage and the formation of replication-mediated DNA double-strand breaks (DSBs), which occurs in the post-treatment cell cycle [12]. These events provoke the activation of ATR und ATM, and downstream CHK1 and CHK2, respectively, as well as p53 phosphorylation [13].

Upon genotoxic stress, p53 can be phosphorylated at different sites. p53 phosphorylated at serine 15 (p53ser15) and serine 20 (p53ser20) results from ATM/ATR-CHK2/CHK1 activation, while phosphorylation at serine 46 (p53ser46) results from activation of the kinase HIPK2 (for review, see [14]). We have recently shown that this also occurs in glioblastoma cells upon treatment with TMZ. We also showed that p53ser46 exerts a pro-apoptotic function as downregulation of HIPK2, the kinase responsible for this phosphorylation, attenuated significantly the level of apoptosis in TMZ-treated LN-229 glioblastoma cells [15]. 
In light of the hypothesis outlined above, according to which low doses elicit pro-survival and high doses pro-death functions, we wondered whether the dose-response of key players of DDR shows the hypothesized threshold. Here, we present data showing the non-existence of threshold doses for $\gamma \mathrm{H} 2 \mathrm{AX}$, p53ser15, p53ser46, apoptosis, autophagy and senescence in the p53 expressing LN-229 glioblastoma cell system.

\section{Results}

\subsection{Dose Response and Time Dependence of p53, p-p53Ser15 and p-53Ser46 in Temozolomide Treated Glioblastoma Cells}

To determine the dose-response of total p53, the pro-survival form p-p53Ser15 and the pro-death form p-53Ser46, Western blot experiments were performed using the line LN-229. This glioblastoma line bears $\mathrm{p} 53$ that harbours a point mutation, which however retains the trans-activating activity of p53 [16]. Therefore, the line can be considered functionally p53 wild-type. LN-229 is MGMT deficient [17]. We further used the isogenic line LN-229MGMT, which was stably transfected with human MGMT cDNA and thus expresses MGMT [18], in order to find out whether the responses observed are triggered by the specific TMZ-induced DNA damage $O^{6} \mathrm{MeG}$. The p53 expression levels were determined 24 and $72 \mathrm{~h}$ after the addition of TMZ to the medium of exponentially growing cells. As shown in Figure 1A, the total p53 and p-p53ser15 protein levels went up with increasing TMZ doses $24 \mathrm{~h}$ after treatment while the p-p53ser46 protein level remained nearly unaffected. With the highest dose of TMZ in this experimental series $(125 \mu \mathrm{M})$ the total p53 level was 3.7 times above the control group while the expression level of p-p53ser15 reached 10.9 times above the control level where p-p53Ser15 was only marginally detected (Figure 1A for a representative blot and for quantification Figure 1C). The finding that, in contrast to p-53Ser15, p-p53ser46 was not induced $24 \mathrm{~h}$ after treatment indicates that there is a sequential activation of pro-survival and pro-death factors in glioblastoma cells exposed to TMZ. In LN-229MGMT, we did not observe any significant increase in p53, p-p53ser15 and p-p53ser46 (Figure 1A, right panel), demonstrating that the effects observed were triggered by the $\mathrm{O}^{6} \mathrm{MeG}$ lesion, which is specifically repaired by MGMT.

After $72 \mathrm{~h} \mathrm{TMZ}$ treatment, LN-229 cells displayed increasing signals of p53 and p-p53ser46 (Figure 1B), p-p53ser15 also increased above the control, although this was moderate compared to p53 and p-p53ser46 (Figure 1B and for quantification Figure 1D). With the highest dose tested, total p53 accumulated 13.1 times over the control, p-p53ser46 reached 8.9 times, and p-p53ser15 was 5.2 times the control level. In LN-229MGMT cells, p-53Ser46 was not enhanced and p-p53ser15 was only slightly activated, very likely due to residual amounts of non-repaired $O^{6} \mathrm{MeG}$ (Figure 1B, right panel). Overall, the data revealed that p-p53Ser15 is an early response and p-53Ser46 a late response triggered by the TMZ-induced lesion $O^{6} \mathrm{MeG}$. 
A LN-229, $24 \mathrm{~h}$

$\begin{array}{llllllll}0 & 12.5 & 25 & 50 & 75 & 100 & 125 & \mathrm{TMZ} \\ (\mu \mathrm{M})\end{array}$

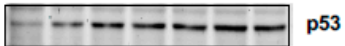

$\begin{array}{lllllllll}1 & 1.9 & 3.3 & 3.9 & 3.9 & 4.1 & 3.7 & \text { I. F. }\end{array}$

- - - - - - - - p53ser15

$\begin{array}{lllllllll}1 & 7.1 & 9.1 & 9.7 & 10.6 & 9.1 & 10.9 & \text { I. F. }\end{array}$

二- - - - - - p-p53ser46

$\begin{array}{lllllllll}1 & 1.1 & 1.1 & 1.3 & 1.5 & 1.8 & 1.8 & \text { I. F. }\end{array}$ - - - - - - HSP 90

B

LN-229, 72 h

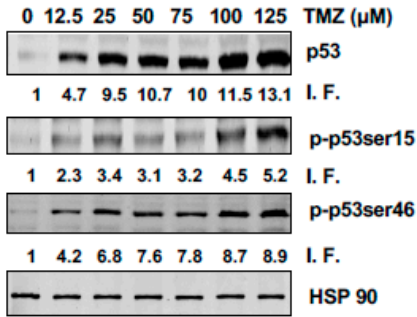

LN-229MGMT, $24 \mathrm{~h}$

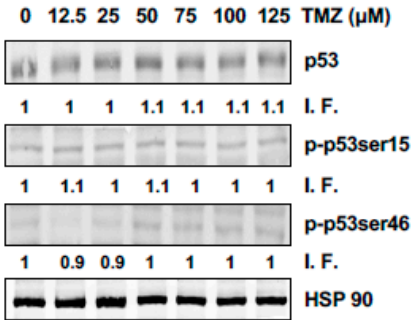

LN-229MGMT, $72 \mathrm{~h}$

$\begin{array}{llllllll}0 & 12.5 & 25 & 50 & 75 & 100 & 125 & \mathrm{TMZ} \\ (\mu \mathrm{M})\end{array}$

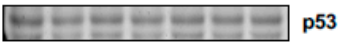

$\begin{array}{llllllllll}1 & 1 & 1 & 1.1 & 1 & 1.1 & 1.1 & \text { l. F. }\end{array}$

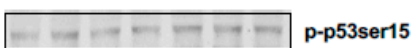

$\begin{array}{lllllllll}1 & 1.7 & 1.4 & 1.5 & 1.8 & 2 & 2.1 & \text { I. F. }\end{array}$

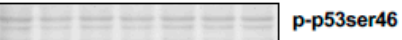

$\begin{array}{lllllllll}1 & 1 & 1.1 & 1 & 1.1 & 1 & 1 & \text { I. F. }\end{array}$

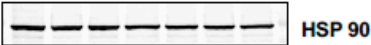

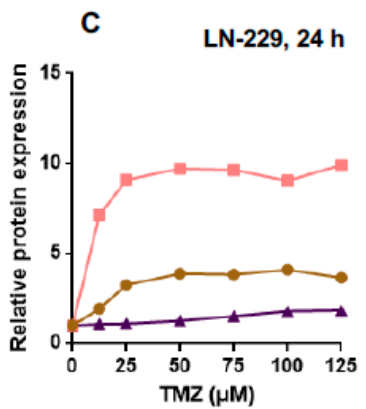

D

LN-229, 72 h

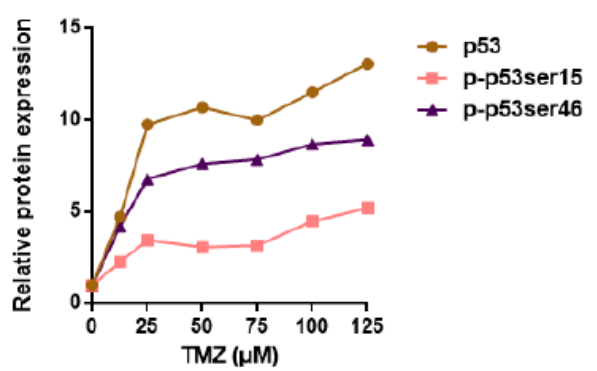

Figure 1. p53 expression and phosphorylation levels of p-p53ser15 and p-p53ser46 in LN-229 and LN-229MGMT cells treated with doses of TMZ up to $125 \mu \mathrm{M}$. (A) LN-229 and LN-229MGMT cells were exposed to doses of TMZ between 0 and $125 \mu \mathrm{M}$. $24 \mathrm{~h}$ later cells were harvested and p53 protein expression, phosphorylation levels of p53ser15 and p53ser46 (p-p53ser15 and p-p53ser46) were detected by Western blot. (B) LN-229 and LN-229MGMT cells were exposed to different doses of TMZ (0 $\mu$ M-125 $\mu \mathrm{M}), 72 \mathrm{~h}$ later p53 protein expression, phosphorylation levels of p53ser15 and p53ser46 were detected by Western blot. HSP90 was used as the loading control. I.F. means induction factor. (C) Relative expression levels of total p53, p-p53ser15 and p-p53ser46 in LN-229 cells $24 \mathrm{~h}$ and (D) $72 \mathrm{~h}$ after addition of TMZ to the medium. The blots were quantified using the Odyssey image analysis system with ImageJ software and plotted on a liner scale.

\subsection{Dose Response and Time-Course of Apoptosis Induction}

To compare the sequence of anti- and pro-apoptotic p53 with cell death induction, we measured apoptosis and necrosis in LN-229 and LN-229MGMT after TMZ treatment in a dose-range up to $125 \mu \mathrm{M}$ by AV/PI staining and flow cytometry. Although $72 \mathrm{~h}$ after exposure to TMZ, the p-p53ser46 level was significantly enhanced (Figure 1B), the apoptosis level stayed low and was not significantly above the control level (Figure 2A). Apoptosis in LN-229 started to increase $96 \mathrm{~h}$ after TMZ exposure, and reached its maximum at 120 and $144 \mathrm{~h}$ (Figure 2A,E,F). This confirms previous observation that $\mathrm{O}^{6} \mathrm{MeG}$ triggered apoptosis is a late response. Of note, the cells were kept in an exponentially growing state throughout the whole examination period. Apoptosis in LN-229 reached a saturation level at $>50 \mu \mathrm{M}$, presumably because of other endpoints that were concomitantly induced such as senescence and autophagy [19]. Necrosis (defined as AV+PI+) was only marginally induced (Figure 2C), supporting our previous finding that $\mathrm{O}^{6} \mathrm{MeG}$ is a powerful apoptotic lesion. In LN-229MGMT cells, 
neither apoptosis nor necrosis was induced with all doses and time points assayed (Figure 2B,D), demonstrating that $O^{6} \mathrm{MeG}$ was responsible for the cytotoxic effects observed.


Figure 2. Apoptosis and necrosis levels in LN-229 and LN-229MGMT cells after TMZ treatment with doses up to $125 \mu \mathrm{M}$. (A,B) Apoptosis and (C,D) necrosis induced by TMZ in LN-229 and LN-229MGMT cells, detected by AV/PI double-staining and flow cytometry. Data were obtained 72, 96, 120 and $144 \mathrm{~h}$ after TMZ exposure. Data were analysed using BD FACSDiva and the Prism software. $p$-values of $<0.05$ are marked as ${ }^{*}, p<0.01$ as ${ }^{* *}, p<0.001$ as ${ }^{* * *}$ and $p<0.0001$ as ${ }^{* * * *}$. (E,F) Apoptosis as a function of post-exposure time in LN-229 cells treated with $25 \mu \mathrm{M}$ (panel E) and $75 \mu \mathrm{M}$ TMZ (panel F).

\subsection{Is There a Threshold in p53, p-p53ser15 and p-p53ser46 Induction?}

Next, we addressed the question of whether there is a threshold in the dose-response in LN-229 cells. For this experimental series, we applied TMZ in a low dose range of up to $20 \mu \mathrm{M}$. Cells were harvested from exponentially grown cultures $24 \mathrm{~h}$ and $72 \mathrm{~h}$ after the onset of treatment and total cell extracts were subjected by Western blot analysis. As shown in Figure 3A, in the low dose range and measured $24 \mathrm{~h}$ after TMZ exposure, p-p53ser 15 was the most sensitive indicator for DNA damage, which increased with increasing dose. After $72 \mathrm{~h}$ exposure, the p-p53ser46 level was also increasing (Figure 3B). As expected on the basis of previous results, in LN-229MGMT all effects were vanished (Figure 3A,B left panels). The results indicate that after low dose TMZ treatment, the pro-survival 
factor p-p53ser15 is phosphorylated first (and quite early) compared to the pro-death factor p-p53ser46, which gets activated at a later stage.

A

LN229, $24 \mathrm{~h}$

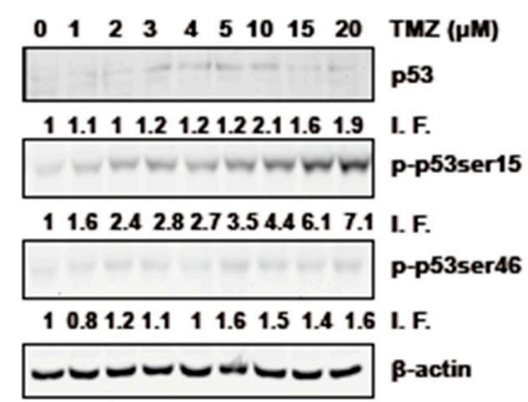

$\mathbf{B}$

LN229, 72 h

$\begin{array}{llllllllll}0 & 1 & 2 & 3 & 4 & 5 & 10 & 15 & 20 & \mathrm{TMZ} \\ (\mu \mathrm{M})\end{array}$

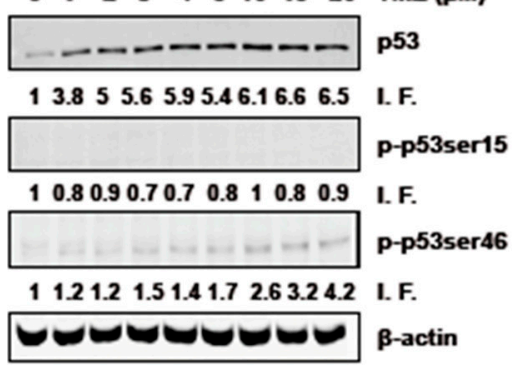

LN229MGMT, 24 h

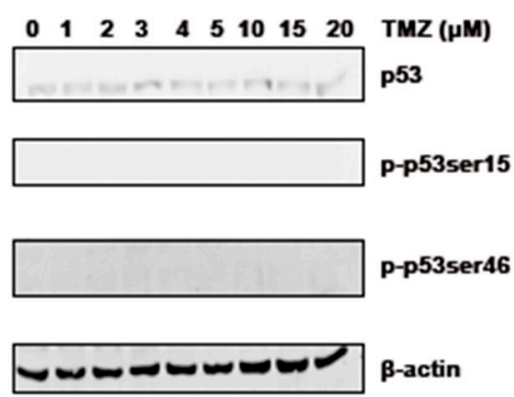

LN229MGMT, 72 h
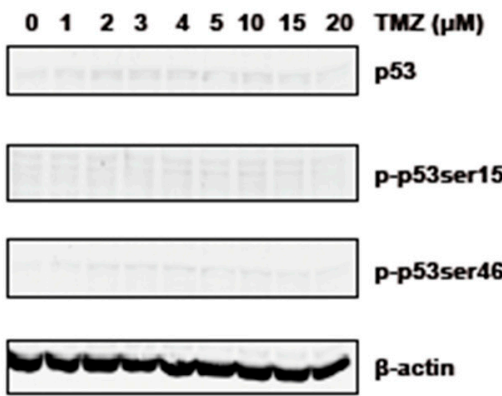

C

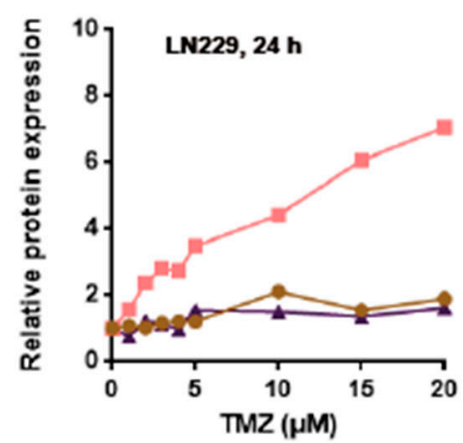

D

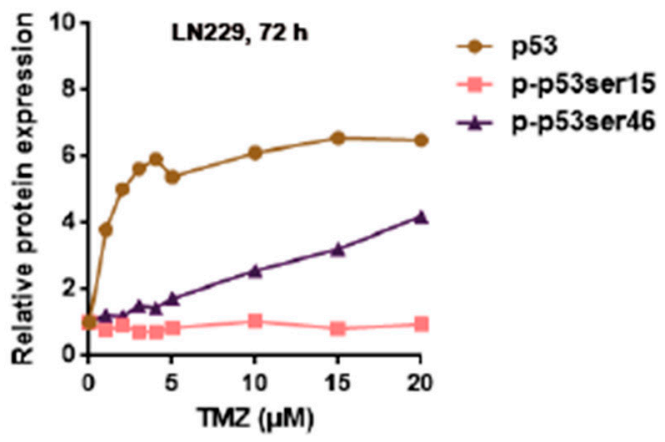

Figure 3. p53 expression and phosphorylation levels of p-p53ser15 and p-p53ser46 in LN-229 and LN-229MGMT cells treated with low doses of TMZ (up to $20 \mu \mathrm{M}$ ). (A) LN-229 and LN-229MGMT cells were exposed to different doses of TMZ and $24 \mathrm{~h}$ later cells were lysed onto the plates, protein extracts were obtained and total p53 protein and p-p53ser15 and p-p53ser46 were detected by Western blot analysis. (B) The same was performed $72 \mathrm{~h}$ after TMZ treatment. $\beta$-actin was used as loading control. I.F. means induction factor, which is related to the non-exposed control. (C,D) Relative expression levels of p53, p-p53ser15 and p-p53ser46 in LN-229 cells 24 and $72 \mathrm{~h}$ after TMZ treatment. Blots were quantified and analysed with ImageJ software. Data from representative experiments are shown.

Originally, we suspected that the dose-response for the pro-apoptotic p-p53ser46 would show a threshold. This, however, was not the case. As revealed by the quantification in Figure 3C,D, there is a linear increase in the amount of p53, p-p53Ser15 and p-p53Ser46. The total p53 level already reached saturation with a dose of $5 \mu \mathrm{M}$. The increase of p-p53ser15 (24 h) and p-p53ser46 (72 h) was linear over the whole dose range tested. 
It is also interesting that after $72 \mathrm{~h}$, the p-p53Ser15 dropped to the control level (Figure 3D), indicating this is an early and transient response compared to p-53Ser46, which is a late (Figure 3D, see also Figure 1) and presumably also long-lasting response.

\subsection{Is There a Threshold in Apoptosis Induction?}

Having shown that p-p53Ser46 increases linearly with dose, we measured the dose-response of apoptosis (and necrosis) in LN-229 cells in the same low dose range (0-20 $\mu \mathrm{M}$ TMZ). As shown in Figure $4 \mathrm{~A}$, there is a linear increase (best fit) in the level of apoptosis without any obvious threshold dose. The dose that displayed a significant increase above the control level was $2.5 \mu \mathrm{M}$. Again, necrosis was not significantly induced (not shown) and MGMT expressing cells were effect-negative (Figure 4B).

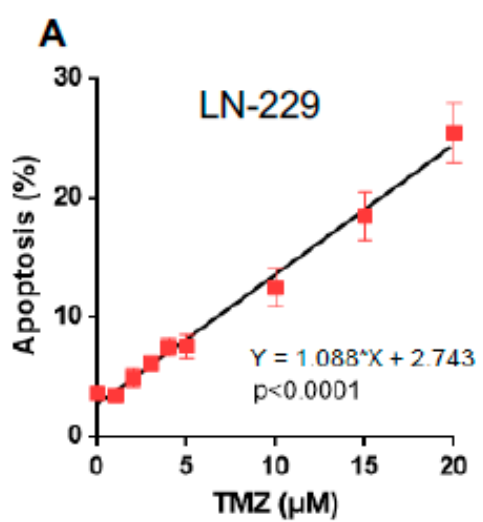

C

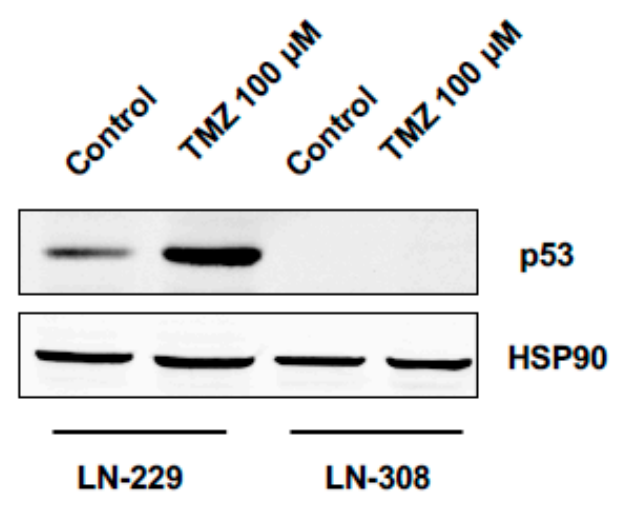

B

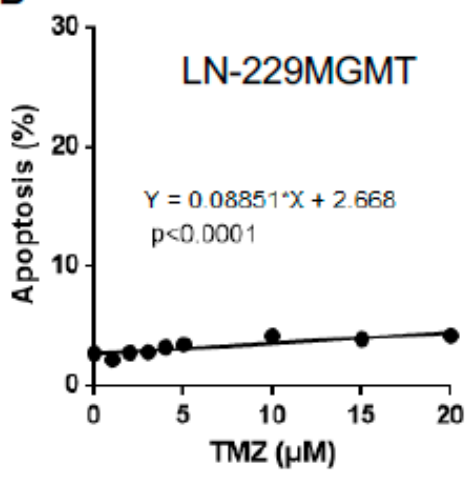

D

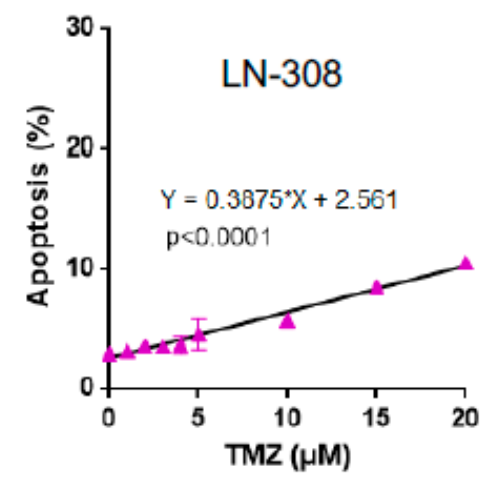

Figure 4. TMZ-induced apoptosis as a function of dose of TMZ dose in LN-229, LN-229MGMT and p53 lacking LN-308 cells. (A) Apoptosis as measured $120 \mathrm{~h}$ after TMZ exposure as a function of dose in LN-229 cells and (B) LN-229MGMT cells. Data are the mean of three independent experiments. (C) LN-229 and LN-308 cells were exposed to $100 \mu \mathrm{M}$ TMZ, protein extracts were collected $72 \mathrm{~h}$ later and the p53 protein expression was detected by Western blot. HSP90 was used as loading control. (D) Apoptosis in LN-308 cells as a function of dose of TMZ measured $120 \mathrm{~h}$ after TMZ treatment. Linear regression analysis was done as described in Materials and Methods.

To explore the possibility that p53 is responsible for the lack of a no-effect threshold, another glioma cell line, LN-308, was introduced in this step of analysis. LN-308 is completely lacking p53 (Figure 4C) due to gene deletion [16]. It is also MGMT deficient (Supplementary Materials, Figure S3). Nevertheless, in order to avoid any effects caused by residual MGMT not detectable by the assays, we routinely pre-treated the cells with $O^{6} \mathrm{BG}$. The data shown in Figure $4 \mathrm{D}$ revealed that LN-308 
cells are more resistant than LN-229 to TMZ-induced apoptosis. The best fit of the dose-response curve was linear and did not reveal a threshold.

To verify the data, colony formation assays were employed, which are considered to be highly sensitive for measuring reproductive cell death. After exposing LN-229, LN-229MGMT and LN-308 cells plated on dishes to TMZ and allowing them to grow for about two weeks, the formed colonies were counted. The survival fraction declined dose-dependently in LN-229 and LN-308. For LN-229 cells, the survival curves did not show a shoulder (Figure 5), supporting the view that there is no threshold for the induction of cell death in this line. In the dose range used, LN-229MGMT cells were strongly protected against TMZ-induced cell death, showing only a slight decline in their colony-forming ability (Figure 5). For LN-308 cells, the survival curve displayed only a marginal shoulder (Figure 5 and Supplementary Material, Figure S4). Overall, the data confirmed the results obtained in the apoptosis assays.
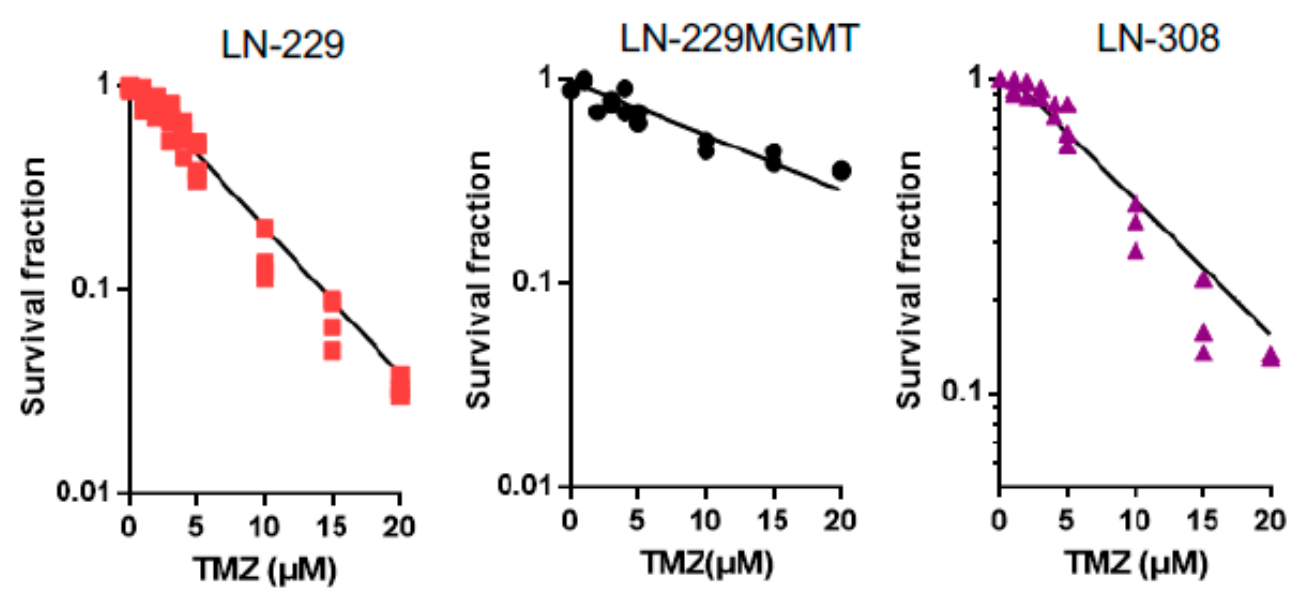

Figure 5. Survival (colony formation) as a function of TMZ dose in LN-229, LN-229MGMT and p53 lacking LN-308 cells. Colony survival assays with LN-229, LN-229MGMT and LN-308 cells exposed to different concentrations of TMZ. Regression lines are the best fit and drawn following computer analysis.

\subsection{Dose-Response of TMZ-Induced Senescence and Autophagy}

In a previous work, we showed that TMZ induces not only apoptosis, but also senescence and autophagy in LN-229 cells [19]. Therefore, we wondered whether senescence and autophagy are induced in the same dose range as apoptosis and whether there is a threshold in the dose-response curves. For comparison, senescence and autophagy were also determined in p53 deficient LN-308 cells. Senescence induced by TMZ increased as a linear function of dose (Figure 6A). Similar to apoptosis, MGMT protected against TMZ-induced senescence (Figure 6B), indicating the primary trigger is $O^{6} \mathrm{MeG}$. In LN-308 cells, the slope of the senescence curve was lower than in LN-229 cells, and therefore, comparatively high doses of TMZ have to be used to significantly induce senescence. Extrapolation of the dose-response curves indicated the non-existence of a threshold (Figure 6C). 

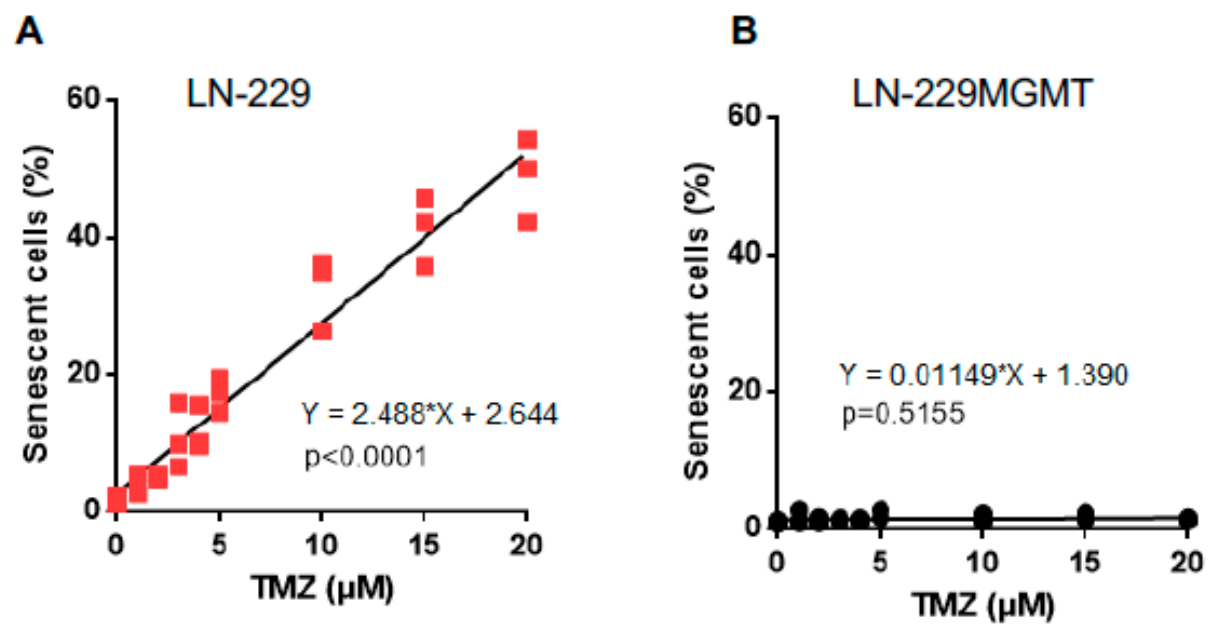

C

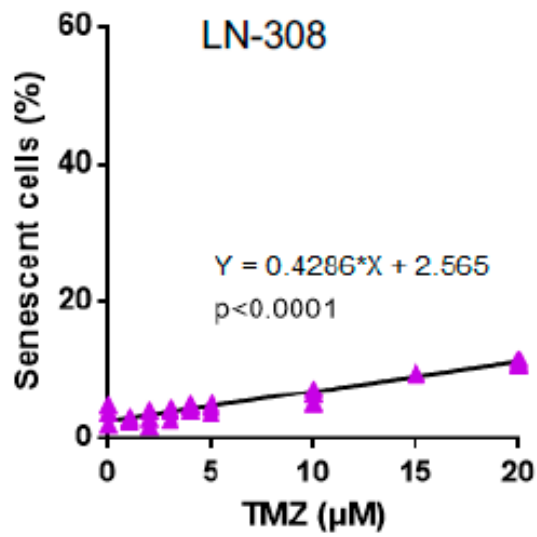

Figure 6. TMZ-induced senescence in LN-229, LN-229MGMT and LN-308 cells. (A) LN-229, (B) LN-229MGMT and (C) LN-308 cells were exposed to TMZ in the dose range of 0-20 $\mu \mathrm{M}$. $96 \mathrm{~h}$ later cells were collected, stained with $\mathrm{C}_{12}$ FDG for $15 \mathrm{~min}$, and analysed by flow cytometry. Regression lines represent the best fit of data obtained.

The autophagy response was similar to senescence. TMZ induced more autophagy in LN-229 than in LN-308 cells (Figure 7A,C), while LN-229MGMT showed no response at all (Figure 7B). Taken together, the results show that p53 proficient LN-229 cells are more sensitive than p53 deficient LN-308 cells as to TMZ-induced apoptosis, senescence and autophagy. No threshold was observed for these endpoints in LN-229 and LN-308 cells. 
A
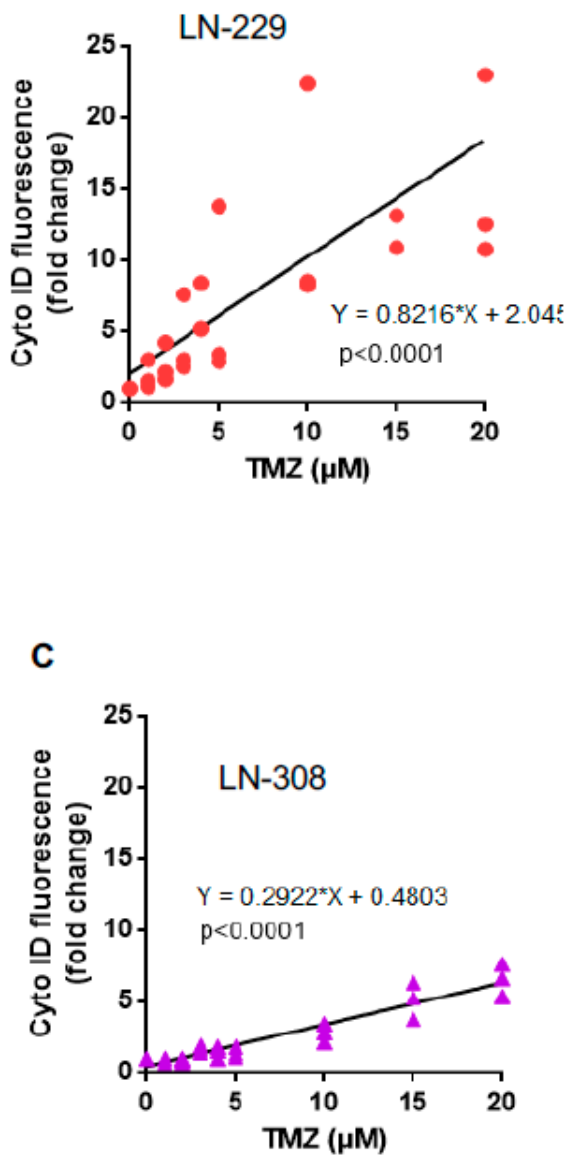

B

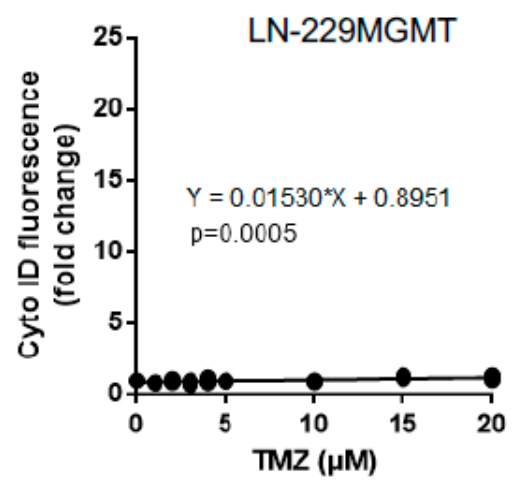

Figure 7. TMZ-induced autophagy in LN-229, LN-229MGMT and LN-308 cells. (A) LN-229, (B) LN-229MGMT and (C) LN-308 cells were exposed to TMZ in the dose range of 0-20 $\mu \mathrm{M} .96 \mathrm{~h}$ later cells were collected and analysed. The results were shown by Cyto ID fluorescence fold change and compared with control samples. Control samples in the three cell lines were set to 1 .

\subsection{Dose-Response of TMZ-Induced DNA Double-Strand Breaks}

The endpoints we have assessed are triggered by the primary lesion $O^{6} \mathrm{MeG}$, whose processing gives rise to DSBs that are considered to be the ultimate trigger of p53 stabilization and cell death [13]. Therefore, different cell death responses could be the result of differences in DSB formation. Thus, the more sensitive p53 proficient LN-229 cells might exhibit better $O^{6} \mathrm{MeG}$ processing resulting in DSBs than LN-308 cells upon treatment with TMZ. To explore this hypothesis, the $\gamma \mathrm{H} 2 \mathrm{AX}$ foci assay was used, which is an accepted indicator of DSBs [20,21]. The cells (LN-229, LN-229MGMT and LN-308) were treated with 0-20 $\mu \mathrm{M} \mathrm{TMZ}$ and, $72 \mathrm{~h}$ later, the $\gamma \mathrm{H} 2 \mathrm{AX}$ foci were determined and quantified. The $\gamma \mathrm{H} 2 \mathrm{AX}$ foci in LN-229 showed a liner increase with dose of TMZ (Figure 8A) and no threshold was obvious. In LN-229MGMT cells, DSBs were not induced at significant level in the whole dose range (Figure 8B). In LN-308, the DSB frequency was very similar to LN-229. The increase was linear and, again, no threshold could be detected (Figure 8C). The similar frequencies of DSBs in LN-229 and LN-308 indicate that sensitivity differences between the cell lines are the result of downstream events triggered by DSBs, presumably through p53. 


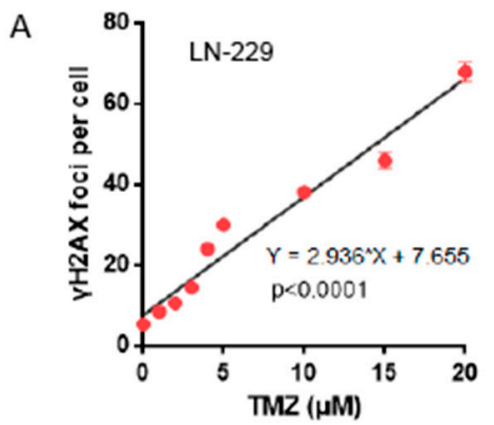

B
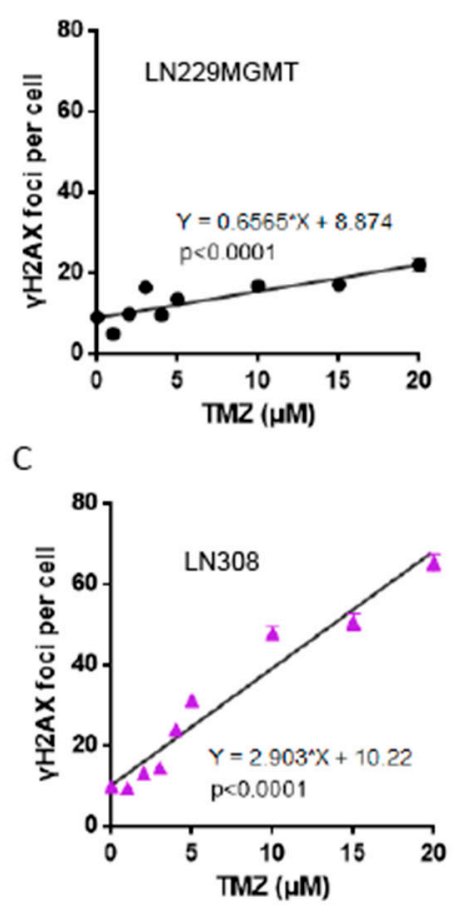

Figure 8. $\gamma \mathrm{H} 2 \mathrm{AX}$ foci as a function of dose of TMZ in LN-229, LN-229MGMT and LN-308 cells. Cells were exposed to TMZ in the dose range of 0-20 $\mu \mathrm{M} .72 \mathrm{~h}$ later cells were fixed, stained for $\gamma \mathrm{H} 2 \mathrm{AX}$ and foci were quantified by the Metafer system in (A) LN-229, (B) LN-229MGMT and (C) LN-308 cells. Data are the mean of several experiments and were assessed by linear regression analysis.

\section{Discussion}

The DNA methylating agent temozolomide is a first-line drug in the treatment of high-grade malignant glioma. It is effective in inducing cell death if the tumor lacks MGMT or expresses it at low level, i.e., $<30 \mathrm{fmol} / \mathrm{mg}$ protein [22]. These tumors are defined as "methylated" because of MGMT promoter CpG methylation, which correlates with silencing of the gene [23] and deficient or low MGMT protein expression and enzyme activity [24]. Since $O^{6} \mathrm{MeG}$ induced by TMZ (and other methylating anticancer drugs) is a toxic DNA damage, it is understandable that MGMT deficiency (determined, e.g., by promoter methylation) leads to responsiveness of the tumor $[25,26]$. Despite these well-known relationships, the prognosis of glioblastoma, which account for up to $70 \%$ of high-grade malignant glioma, is bleak as the median length of survival is only 14.6 months (12.6 and 23.4 months in the MGMT-unmethylated and MGMT-methylated subgroups, respectively) [27]. Although recent phase III clinical trials showed that the median overall survival for adult patients with newly diagnosed glioblastoma can reach up to 20 months in the control cohorts, indicating a trending increase in median overall survival, the prognosis is still bad with 5-year overall survival rates of less than 10\% (for references see [28]). Treatment with TMZ occurs daily along different schedules [29-32]. The serum concentration of TMZ has been determined to be in the range of up to $30 \mu \mathrm{M}$, with a half-life 
of about $2 \mathrm{~h}$ [33-38]. In a therapeutic setting with a single oral dose of $150 \mathrm{mg} / \mathrm{m}^{2}$, the peak plasma concentration was, on average, $28.4 \mu \mathrm{M}(5.5 \mu \mathrm{g} / \mathrm{mL})$ and the brain interstitium concentration $1.5 \mu \mathrm{M}$ $(0.3 \mu \mathrm{g} / \mathrm{mL})$ [39]. In another study TMZ was determined following oral $200 \mathrm{mg} / \mathrm{m}^{2} \mathrm{TMZ}$, with a plasma peak level of $72 \mu \mathrm{M}$ and a cerebrospinal fluid level of $9.9 \mu \mathrm{M}$ [40]. Thus, the TMZ concentration at the target organ seems to be rather low and it is reasonable to suppose, notably in view of the high recurrence rate, that the TMZ level is not high enough in order to exert a killing effect on residual (post-operative) glioblastoma cells. This notion is fueled by the supposition that at low dose levels cell death is not induced, which goes back to the general paradigm that low DNA damage levels induce survival functions, whereas high DNA damage levels activate cellular death pathways [1-6]. This view implies that DNA damage thresholds do exist that regulate the balance between life and death. This work was aimed at proving or disproving this widely accepted hypothesis.

First, we have shown that in LN-229 and LN-308 glioblastoma cells, which are functionally wild-type and mutant for p53, respectively [16], the amount of DSB ( $\gamma \mathrm{H} 2 \mathrm{AX}$ foci) increases as a linear function of dose. TMZ does not need metabolic activation. It spontaneously decomposes, yielding carbenium ions that methylate DNA dose-dependently. From this it is reasonable to conclude that $\mathrm{O}^{6} \mathrm{MeG}$ is induced as a linear function of dose. The linear dose-response for DSBs indicates that the rate of conversion of $\mathrm{O}^{6} \mathrm{MeG}$ into DSB is independent on dose, and there is no defense at low dose levels that prevents the formation of DSBs in LN-229 and LN-308 cells. In this model system, we determined about $60 \mathrm{DSBs}$ with a dose of $20 \mu \mathrm{M}$ TMZ. The amount of $O^{6} \mathrm{MeG}$ induced under these conditions is not known.

We further show in Western blot experiments that p53, p-p53ser15 and p-p53ser46 increase up to a saturation level as a linear function of dose. This was a surprising finding since it collides with the view that low DNA damage triggers survival and high DNA damage triggers death functions. Upon TMZ treatment, p-p53ser15 results from ATR (ATM) and downstream CHK1 (CHK) activation [41], which is likely the result of blocked replication forks and DSBs formed on collapsed forks. The linear dose-response suggests that even low $\mathrm{O}^{6} \mathrm{MeG}$ and DSB levels induced by TMZ are able to activate the DNA damage checkpoint kinases that phosphorylate 53 at serine 15 . Unexpectedly, p-p53ser46 was also generated at low dose levels without a detectable threshold. p-p53ser46 results from activation of the stress kinase HIPK2 [42]. The pathway of HIPK2 activation in general [43] and following TMZ in glioblastoma cells, including LN-229, has been described [15]. The available data suggest that primarily ATR and following secondary activation, also ATM, phosphorylate SIAH1, the inhibitor of HIPK2 [44,45]. This leads to degradation of SIAH1 and liberation and stabilization of HIPK2, which in turn phosphorylates p53 at serine 46 (see Figure 9). The linearity of p-p53ser46 accumulation indicates that ATR (ATM) is able to phosphorylate SIAH1 and thus liberate HIPK2 even at very low TMZ doses.

We have shown that p-p53ser15 and p-p53ser46 become activated following TMZ treatment in a sequential order, with early activation of p-p53ser15 and late activation of p-p53ser46. p-p53ser15 becomes detectable $24 \mathrm{~h}$ after treatment and declines a day later, indicating that this is a transient response. p-p53ser 46 was detected 3 days after treatment and was still detectable when cells started to undergo apoptosis. This is in line with the pro-apoptotic role of this phosphorylated form of p53. 


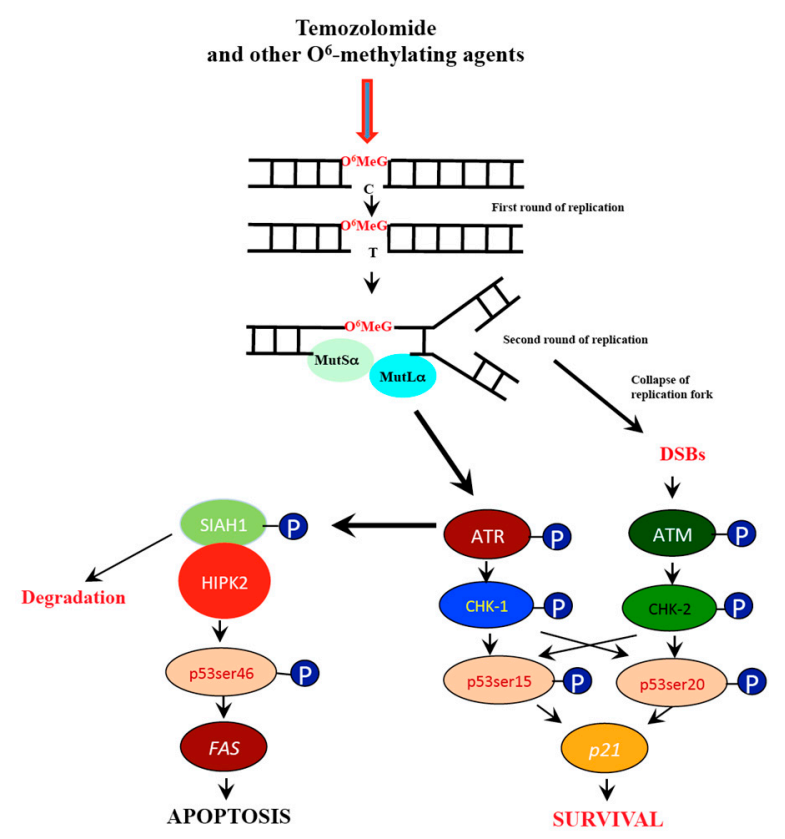

Figure 9. Pathways triggered by $\mathrm{O}^{6}$-methylguanine (a simplified schema). $\mathrm{O}^{6} \mathrm{MeG}$ is processed by MMR resulting in replication blockage and the formation of free DSBs. This gives rise to ATR and ATM and downstream p53 activation. The kinase HIPK2 becomes activated following SIAH1 phosphorylation, which in turn activates p53ser46 that targets the promoter of several pro-apoptotic genes. Although p-p53ser15 can transcriptionally activate DNA repair genes such as DDB2, which is involved in nucleotide excision repair, there is no evidence yet that p53 upregulates DNA repair genes (as an immediate-early response) that are of importance for temozolomide resistance.

In accordance with this is the finding that apoptosis (Figure 4) and reproductive death (Figure 5) of LN-229 cells do not display a clear no-effect threshold. Cell death appears to be a linear function of the dose of TMZ. It is known that p-p53ser46 binds to the promoter of pro-apoptotic genes, including the death receptor FAS (alias CD95/APO1), and thus stimulates its transcription [46]. This was recently shown to occur upon TMZ in LN-229 cells [15]. Obviously, there is no threshold for p-p53ser46 transactivation activity in this cell system.

Similar to apoptosis, DNA damage-induced senescence (Figure 6) and autophagy (Figure 7) were induced as a linear function of the dose of TMZ. In MGMT expressing cells, TMZ was ineffective in inducing these effects (doses up to $50 \mu \mathrm{M}$ ) suggesting that they were triggered by $\mathrm{O}^{6} \mathrm{MeG}$. Previously, we have shown that senescence and autophagy are regulated by the same upstream damage response pathway that regulates apoptosis [19]. The linearity for these endpoints indicates that pro- and anti-death functions are induced simultaneously at each dose level. From the therapeutic point of view, the finding points to the need of inhibiting the pro-survival functions senescence and autophagy in a way that cells preferentially enter the death pathway.

Finally, we observed that the p53 deficient glioblastoma cell line, LN-308 is more resistant to the induction of apoptosis by TMZ. This finding is compatible with our previous observations according to which MGMT deficient p53wt glioma cells are more sensitive to the cytotoxic (apoptotic) effect of TMZ than MGMT deficient p53 mutated cells that lack the transactivation activity of p53 [47]. The p-53 independent apoptotic pathway of glioblastoma cells is bound on the endogenous mitochondrial pathway, which seems to be more refractory than the p53 regulated death receptor pathway [18]. Of note, p53 also stimulates the mitochondrial cell death route by supporting the translocation of $\mathrm{BAX}$ to the outer mitochondrial membrane and sequestering $\mathrm{Bcl}-2$, leading to cytochrome $\mathrm{C}$ release and apoptosome formation [48,49]. It is therefore reasonable to conclude that p53-driven apoptosis rests on both p-p53ser46 promoter activation and exacerbation of mitochondrial damage through cytoplasmatic p53. 


\section{Conclusions and Implications}

Although we are aware that this study needs extension to other cell lines and tumor models, LN-229 provides an example where the paradigm that low doses activate survival and high doses death functions does not apply. Regarding DNA repair, it is known that p-p53ser15 triggers the activation of DNA repair genes, which causes protection against genotoxins [7]. According to our experience with different cell types and genotoxins, the most robust p53-stimulated repair genes encode DDB2 and XPC as well as the translesion polymerase Pol eta ( $\mathrm{Pol} \mathrm{H})$ [50]. However, these genotoxic stress-inducible repair proteins are not involved in the repair of TMZ-induced DNA methylation damage. A reasonable candidate for causing a threshold is MGMT. Thus, from work that included bacteria to humans, it became clear that MGMT mediated DNA repair gives rise to a mutagenic and toxic threshold [11,51,52]. However, a search for an adaptive response in brain cancer cells revealed that MGMT is not inducible by TMZ, which is clearly different from rodent cells in which MGMT was shown to be upregulated following genotoxic stress [53] in a p53 dependent manner [54]. Therefore, lack of induction of repair of $O^{6} \mathrm{MeG}$ in glioma cells is surely a contributing factor for the non-existence of a threshold. If ATR/ATM becomes activated even with low damage levels and also triggers senescence, autophagy and apoptosis, the important question arises as to the mechanism that makes the switch between the pathways. This is clearly an attractive area of future research.

In view of the limited amount of cell lines used in this study, it is too early for clinical implications. Nevertheless, the data may be taken to indicate that even a low dose of TMZ is able to elicit a cytotoxic response in p53 wild-type and MGMT lacking tumors. Of note, a prerequisite for $\mathrm{O}^{6} \mathrm{MeG}$ induced cytotoxicity is cell proliferation. If a fraction of tumor cells is released in a senescent state, it will no longer be subjected to $O^{6} \mathrm{MeG}$ triggered apoptosis. This might especially be the case if cells are treated repetitively. Therefore, on the basis of the results presented here, the metronomic dose protocol (drug application at low and frequent doses) bears beneficial effects by exacerbating cytotoxicity, but also adverse effects since the fraction of non-proliferating (senescent) cells might be increasing with each consecutive treatment dose. It should also be considered that TMZ is usually given concomitantly with ionizing radiation (usually 2 Gy per treatment), which may additionally ameliorate the fraction of non-proliferating tumor cells. If the arrest state is transient, it is conceivable that the fraction of senescent cells at the end of therapy contributes to recurrence, which is usually the unfortunate case for glioblastomas. Again, we are aware of the limitations of the study, which rests on comparison of only three cell lines (LN-229, LN-220MGMT and LN-308). It provides, however, an example of lack of threshold doses in cell death responses $(\gamma \mathrm{H} 2 \mathrm{AX}$, p53ser15 and p53ser46, apoptosis, autophagy and senescence) if MGMT is lacking. The data warrant further studies with a larger set of well-defined cell lines, stem cells and tumors in situ prior to and after therapy.

\section{Materials and Methods}

\subsection{Cell Lines and Culture Conditions}

The human glioma cell line LN-229 was purchased from American Type Culture Collection (ATCC), the human glioma line LN-308 were a generous gift from Prof. Dr. M. Weller (Laboratory of Molecular Neuro-oncology, University of Zurich, Switzerland). Upon receipt, the cells were amplified for cryopreservation in liquid- $\mathrm{N}_{2}$ and freshly thawed cell stocks were used for every battery of tests. LN-229, LN-308 and the LN-229MGMT transfected cells [19] were cultured in DMEM (Gibco, Life Technologies Corporation, Paisley, UK) supplemented with 10\% FBS and penicillin/streptomycin (PAA Laboratories, $\mathrm{GmbH}$, Cölbe, Germany). Cells were maintained at $37^{\circ} \mathrm{C}$ in a humidified $5 \%$ $\mathrm{CO}_{2}$ atmosphere. 


\subsection{Cell Seeding and Growth}

Cells were cultured in DMEM supplemented with $10 \%$ fetal bovine serum. Cells were seeded $24 \mathrm{~h}$ before any treatment to settle down and get ready for knockdown and treatments. Seeding density was such that exponential cell growth was ensured for the whole experimental period.

\subsection{Drugs and Drug Treatment}

The MGMT inhibitor $O^{6}$-benzylguanine $\left(O^{6} \mathrm{BG}\right.$, Sigma-Aldrich, Steinheim, Germany) was dissolved in DMSO to a stock concentration of $10 \mathrm{mM}$, aliquoted and stored at $-20^{\circ} \mathrm{C}$. To inactivate any residual MGMT, $1 \mathrm{~h}$ before the addition of TMZ $\mathrm{O}^{6} \mathrm{BG}$ was added to the medium. The final concentration of $O^{6} \mathrm{BG}$ in DMEM was $10 \mu \mathrm{M}$. Temozolomide was a generous gift of Dr Geoff Margison (University of Manchester, UK). Stocks were dissolved in dimethyl sulfoxide (DMSO, Carl Roth $\mathrm{GmbH}$, Karlsruhe, Germany), diluted in two parts sterile $\mathrm{dH}_{2} \mathrm{O}$ to a concentration of $35 \mathrm{mM}$, aliquoted and stored at $-80{ }^{\circ} \mathrm{C}$ until use. After thawing, the stock solution was sonicated for $10 \mathrm{~s}$ to help TMZ dissolution. Cells were exposed to TMZ by directly adding the aqueous TMZ stock solution to the medium.

\subsection{Colony Survival Assays}

Cells were seeded in $6 \mathrm{~cm}$ dishes, treated 1 day later with $\mathrm{TMZ}$ and left to grow in a $\mathrm{CO}_{2}$ incubator until colonies appeared (microscopic control). Colonies were fixed in methanol and stained $(1.25 \%$ Giemsa, $0.125 \%$ crystal violet). The plating efficiency represents the number of colonies formed in the control sample/ number of cells seeded in the control sample $\times 100 \%$, and the surviving fraction is the number of colonies after treatment/number of cells seeded $\times$ PE. Colonies containing more than about 50 cells were scored.

\subsection{Apoptosis/Necrosis Flow Cytometry}

For the determination of apoptosis and necrosis the annexin $\mathrm{V} /$ propidium iodide (AV/PI) assay coupled with flow cytometry analysis was used. In brief, for harvest cells in the supernatant were collected in a $15 \mathrm{~mL}$ tube, samples were washed twice with PBS and detached with trypsin/EDTA solution. They were washed twice in PBS and $50 \mu \mathrm{L} 1 \times$ binding buffer and $2.5 \mu \mathrm{L}$ Annexin V/FITC (Miltenyi Biotec $\mathrm{GmbH}$, Bergisch Gladbach, Germany) were added to each sample. Following $15 \mathrm{~min}$ incubation in the dark on ice, $430 \mu \mathrm{L} 1 \mathrm{x}$ binding buffer and $1 \mu \mathrm{g} / \mathrm{mL}$ PI (Sigma-Aldrich, Steinheim, Germany) were added to the cells. Data acquisition was done by a FACS Canto II flow cytometer (Becton Dickinson $\mathrm{GmbH}$, Heidelberg, Germany). Annexin V positive cells were classified as apoptotic while annexin V and PI double-positive cells were classified as necrotic/late-apoptotic. The data were analysed using the BD FACSDiva software. A representative plot of control and treated cells is shown in Supplementary Materials, Figure S1.

\subsection{Whole-Cell Protein Extracts}

Cells were washed twice with PBS and 300-600ul RIPA buffer was added to each sample. The cells were scraped off and transferred to pre-cooled tubes, vortexed and put on ice. Sonication was employed for disrupting cells $(3 \times 10$ pulses $)$ and samples were centrifuged $\left(10 \mathrm{~min}\right.$ at $4{ }^{\circ} \mathrm{C}$, $14,000 \mathrm{rpm}$ ) to obtain the protein extract in the supernatant. Protein concentration was determined by Bradford. The extraction buffer and RIPA buffer recipes were as follows: Extraction buffer: $20 \mathrm{mM}$ tris(hydroxymethyl)aminomethane [TRIS] $\mathrm{HCl} \mathrm{pH}$ 8.5, $1 \mathrm{mM}$ EDTA, 5 \% glycerine, $1 \mathrm{mM}$ $\beta$-mercaptoethanol, $10 \mu \mathrm{M}$ dithiothreitol [DTT], $1 \times$ protease inhibitor cOmplete ${ }^{\mathrm{TM}}$. RIPA buffer: $50 \mathrm{mM}$ Tris (pH 8), $150 \mathrm{mM} \mathrm{NaCl}, 1 \mathrm{mM}$ EDTA, 1\% NP-40, 0.5\% sodium deoxycholate, $0.1 \%$ SDS. This buffer was stored at $4{ }^{\circ} \mathrm{C}$ before use. Prior to use, freshly prepared PMSF $100 \mathrm{mM}$ stock $(10 \mu \mathrm{L})$, $\mathrm{Na}_{3} \mathrm{VO}_{4} 200 \mathrm{mM}$ stock $(10 \mu \mathrm{L})$, DTT $1 \mathrm{M}$ stock $(2 \mu \mathrm{L})$ and $7 x$ protease inhibitor $(142.9 \mu \mathrm{L})$ were added to $835 \mu$ l RIPA buffer to get $1 \mathrm{~mL}$ working buffer. 


\subsection{Western Blot}

Following the separation of proteins by sodium dodecyl sulphate polyacrylamide gel electrophoresis (SDS-PAGE) and transfer to nitrocellulose membranes, the following antibodies were used: Anti- $\beta$-actin (Abcam; Ab8227), anti-HSP90 (Cell Signaling Technology, Frankfurt, Germany; No. 4874), anti-p53 (Santa Cruz Biotechnology, Heidelberg, Germany; sc-126), anti-phospho-p53 (Ser15) (Cell Signaling Technology; No. 9284), anti-phospho-p53 (Ser46) (Becton Dickinson; No. 558245), anti-MGMT (Sigma-Aldrich; HPA032136). Proteins were detected using the Odyssey 9120 Infrared Imaging System (Li-Cor Biosciences, Lincoln, Nebraska, USA). The membrane was dried at room temperature in the dark and scanned with Odyssey. Image J was used for the quantification.

\subsection{Autophagy Assay}

The Cyto-ID kit (ENZO Life Sciences, Lörrach, Germany) was used for quantifying autophagy. Cells were seeded in $6 \mathrm{~cm}$ dishes, being careful that cells were confluent when harvesting. The supernatant from each sample was transferred to a $15 \mathrm{~mL}$ tube, cells were rinsed with PBS and trypsinized with $1 \mathrm{~mL}$ trypsin-EDTA and taken up in $1 \mathrm{~mL}$ fresh medium, which was transferred to a $15 \mathrm{~mL}$ tube for centrifugation (1000 rpm, $5 \mathrm{~min}$ ). The pellet was resuspended in $2 \mathrm{~mL}$ PBS, washed again in PBS and resuspended in $0.25 \mathrm{~mL}$ DMEM with 5\% FBS without phenol red and $0.25 \mathrm{~mL}$ diluted Cyto-ID solution was added to each sample. After resuspension, the samples were incubated $30 \mathrm{~min}$ at $37^{\circ} \mathrm{C}$ in the dark. After centrifugation $(1500 \mathrm{rpm}, 5 \mathrm{~min})$, the supernatant was discarded and the pellet was resuspended in $1 \mathrm{~mL}$ assay buffer. Samples were centrifuged (1500 rpm, $5 \mathrm{~min}$ ) and resuspended in $0.5 \mathrm{~mL}$ assay buffer and transferred into FACS tubes. FACS Canto was employed for the measurement. The data were analysed using the BD FACSDiva software.

\subsection{The $\gamma H 2 A X$ Foci Assay}

For measuring DSBs, the $\gamma \mathrm{H} 2 \mathrm{AX}$ foci assay was employed. The cells were seeded in $6 \mathrm{~cm}$ dishes in plates containing sterile cover slips. When harvesting, the medium was discarded, the samples were washed twice with PBS and cells were fixed in ice cold methanol:aceton $\left(7: 3\right.$ stored at $\left.-20{ }^{\circ} \mathrm{C}\right)$, kept on $4{ }^{\circ} \mathrm{C}$ for exactly $9 \mathrm{~min}$. The fixation solution was removed, samples were rinsed three times with PBS and $2 \mathrm{~mL}$ PBS was added to each dish to keep the cover slips wet. The cover slip was put into a $3 \mathrm{~cm}$ dish (the cells side up), blocked with blocking buffer (5\% BSA in PBS with $0.3 \%$ Triton X-100) for $1 \mathrm{~h}$, the other cover slip was stored at $4{ }^{\circ} \mathrm{C}$ as a backup. The blocking buffer was removed, $50 \mu 1$ of $\gamma \mathrm{H} 2 \mathrm{AX}$ antibody (Cell Signaling; Cat. No. 9718s) (1:1.000 dilution of $\gamma \mathrm{H} 2 \mathrm{AX}$ in PBS with 0.3\% Triton X-100) was added on the cover slip for overnight incubation at $4{ }^{\circ} \mathrm{C}$. After 3 times PBS washing, $50 \mu \mathrm{L}$ of the secondary antibody (Alexa Fluor ${ }^{\circledR} 488$, rabbit green, 1:500 of Alexa Fluor ${ }^{\circledR} 488$ in PBS with $0.3 \%$ Triton $\mathrm{X}-100)$ was added to the cells on the cover slip and incubated at room temperature in the dark for $2 \mathrm{~h}$, followed by three times washing with PBS. The secondary antibody (Alexa Fluor ${ }^{\circledR} 488$ ) was from Life Technologies, Carlsbad, USA. DAPI-Vectashield (Vector Laboratories, Burlingame, CA, USA) and the solution $(1.5 \mu \mathrm{L}$ of $1 \mathrm{mg} / \mathrm{mL}$ DAPI was added in $1 \mathrm{~mL}$ Vectashield mounting medium, and vortexed thoroughly) was prepared freshly for staining. $20 \mu \mathrm{L}$ of the DAPI-Vectashield solution was dropped on the center of one slide, the cover slip was put on the DAPI-Vectashield solution and sealed by nail oil. The slides were kept in the dark at room temperature for $10 \mathrm{~min}$ to dry. The $\gamma \mathrm{H} 2 \mathrm{AX}$ foci numbers were determined using the Metasystem finder version 3.1. Representative pictures of foci are shown in Supplementary Materials, Figure S2.

\subsection{Senescence Measurements with $C_{12}$ FDG Staining}

Premature senescence was determined using $\mathrm{C}_{12} \mathrm{FDG}$ and flow cytometry quantification. In brief, $\mathrm{C}_{12} \mathrm{FDG}$ is a substrate of SA- $\beta$-galactosidase. Upon cleavage it produces a green fluorescence, which can be detected by FACS. Bafilomycin A1 is an inhibitor of vacuolar type $\mathrm{H}^{+}$-ATPase (V-ATPase). It blocks lysosomal acidification and also increases the $\mathrm{pH}$ of lysosomes [55]. Bafilomycin A1 
(Sigma-Aldrich, Steinheim, Germany) was dissolved in DMSO at $0.1 \mathrm{mM}$ stock solution and stored at $-20^{\circ} \mathrm{C}$. The working concentration was $100 \mathrm{nM}$. $\mathrm{C}_{12} \mathrm{FDG}$ (Sigma-Aldrich, Steinheim, Germany) was dissolved in DMSO $\left(20 \mathrm{mM}\right.$ stock solution) and stored at $-20^{\circ} \mathrm{C}$. The stock solution was diluted with fresh medium to get a $2 \mathrm{mM}$ working solution. Cells were seeded and treated $96 \mathrm{~h}$ before the assay was performed. They were incubated with $100 \mathrm{nM}$ bafilomycin $\mathrm{A} 1$ for $1 \mathrm{~h}$ and thereafter with $33 \mu \mathrm{M}$ $\mathrm{C}_{12} \mathrm{FDG}$ for $2 \mathrm{~h}$. All the procedures after $\mathrm{C}_{12} \mathrm{FDG}$ incubation were operated avoiding light. The samples were rinsed with PBS three times, 30s each, harvested with trypsin-EDTA and resuspended in serum containing medium together with the cells in the supernatant. They were collected by centrifugation at $4{ }^{\circ} \mathrm{C}, 100-250 \mathrm{~g}, 5 \mathrm{~min}$. The pellet was resuspended in $0.4-0.5 \mathrm{~mL}$ PBS $\left(4^{\circ} \mathrm{C}\right)$ and cells (titer of about $1 \times 10^{6} / \mathrm{mL}$ ) were measured in a FACS Canto II flow cytometer.

\subsection{Statistical Analysis}

If not clarified specifically, data points show the means of at least three independent experiments and the standard deviation from mean as error bars. For comparison, two-way ANOVA was employed, the calculated $p$-values are displayed: $p$-value $<0.05^{*}, p$-value $<0.005^{* *}, p$-value $<0.001^{* * *}$, $p$-value $<0.0001^{* * * *}$. GraphPad Prism software was used for statistical analysis and graph plotting.

Supplementary Materials: Supplementary materials can be found at http:/ / www.mdpi.com/1422-0067/20/7/ $1562 /$ s1.

Author Contributions: Conceptualization, B.K.; Funding, Y.H. and B.K.; Experimental design, Y.H. and B.K.; Experimental performance, Y.H.; Data evaluation, Y.H. and B.K.; Figures and Statistics, Y.H.; Methodology, Y.H. and B.K.; Supervision, B.K.; Writing primary draft results, Y.H.; Writing, review and editing, B.K.

Funding: This research was funded by the International PhD programme of the Institute of Molecular Biology, University of Mainz, supported by the Boehringer Ingelheim Foundation. It was further supported by the Deutsche Forschungsgemeinschaft (DFG KA724).

Acknowledgments: Yang He was affiliated with and supported by the International PhD programme on Gene Regulation, Epigenetics and Genome Stability, Johannes Gutenberg-University of Mainz, Germany. The work was financially supported by grants of the Deutsche Forschungsgemeinschaft to B.K. (DFG KA724). We gratefully acknowledge assistance by G. Nagel and the valuable experimental advice and support by Wynand P. Roos.

Conflicts of Interest: The authors declare no conflict of interest. The funders had no role in the design of the study; in the collection, analyses, or interpretation of data; in the writing of the manuscript, or in the decision to publish the results.

\section{References}

1. Roos, W.P.; Thomas, A.D.; Kaina, B. DNA damage and the balance between survival and death in cancer biology. Nat. Rev. Cancer 2016, 16, 20-33. [CrossRef] [PubMed]

2. Horvath, M.M.; Wang, X.; Resnick, M.A.; Bell, D.A. Divergent evolution of human p53 binding sites: Cell cycle versus apoptosis. PLoS Genet. 2007, 3, e127. [CrossRef]

3. Vousden, K.H.; Prives, C. Blinded by the light: The growing complexity of p53. Cell 2009, 137, $413-431$. [CrossRef] [PubMed]

4. Oren, M. Decision making by p53: Life, death and cancer. Cell Death Differ. 2003, 10, 431-442. [CrossRef] [PubMed]

5. Zhang, X.P.; Liu, F.; Cheng, Z.; Wang, W. Cell fate decision mediated by p53 pulses. Proc. Natl. Acad. Sci. USA 2009, 106, 12245-12250. [CrossRef]

6. Zhang, X.P.; Liu, F.; Wang, W. Two-phase dynamics of p53 in the DNA damage response. Proc. Natl. Acad. Sci. USA 2011, 108, 8990-8995. [CrossRef] [PubMed]

7. Christmann, M.; Kaina, B. Transcriptional regulation of human DNA repair genes following genotoxic stress: Trigger mechanisms, inducible responses and genotoxic adaptation. Nucleic Acids Res. 2013, 41, 8403-8420. [CrossRef]

8. Villano, J.L.; Seery, T.E.; Bressler, L.R. Temozolomide in malignant gliomas: Current use and future targets. Cancer Chemother. Pharmacol. 2009, 64, 647-655. [CrossRef]

9. Beranek, D.T. Distribution of methyl and ethyl adducts following alkylation with monofunctional alkylating agents. Mutat. Res. 1990, 231, 11-30. [CrossRef] 
10. Kaina, B.; Fritz, G.; Mitra, S.; Coquerelle, T. Transfection and expression of human $O^{6}$-methylguanine-DNA methyltransferase (MGMT) cDNA in chinese hamster cells: The role of MGMT in protection against the genotoxic effects of alkylating agents. Carcinogenesis 1991, 12, 1857-1867.

11. Kaina, B.; Christmann, M.; Naumann, S.; Roos, W.P. MGMT: Key node in the battle against genotoxicity, carcinogenicity and apoptosis induced by alkylating agents. DNA Repair (Amst) 2007, 6, 1079-1099. [CrossRef]

12. Quiros, S.; Roos, W.P.; Kaina, B. Processing of O6-methylguanine into DNA double-strand breaks requires two rounds of replication whereas apoptosis is also induced in subsequent cell cycles. Cell Cycle 2010, 9 , 168-178. [CrossRef] [PubMed]

13. Roos, W.P.; Kaina, B. DNA damage-induced cell death: From specific DNA lesions to the DNA damage response and apoptosis. Cancer Lett. 2013, 332, 237-248. [CrossRef] [PubMed]

14. Matt, S.; Hofmann, T.G. The DNA damage-induced cell death response: A roadmap to kill cancer cells. Cell. Mol. Life Sci. 2016, 73, 2829-2850. [CrossRef]

15. He, Y.; Roos, W.P.; Wu, Q.; Hofmann, T.G.; Kaina, B. The Siah1-Hipk2-p53ser46 damage response pathway is involved in temozolomide-induced glioblastoma cell death. Mol. Cancer Res. 2019. [CrossRef] [PubMed]

16. Ishii, N.; Maier, D.; Merlo, A.; Tada, M.; Sawamura, Y.; Diserens, A.C.; Van Meir, E.G. Frequent co-alterations of tp53, p16/cdkn2a, p14arf, pten tumor suppressor genes in human glioma cell lines. Brain Pathol. 1999, 9, 469-479. [CrossRef] [PubMed]

17. Aasland, D.; Reich, T.R.; Tomicic, M.T.; Switzeny, O.J.; Kaina, B.; Christmann, M. Repair gene $\mathrm{O}(6)$-methylguanine-DNA methyltransferase is controlled by SP1 and up-regulated by glucocorticoids, but not by temozolomide and radiation. J. Neurochem. 2018, 144, 139-151. [CrossRef] [PubMed]

18. Roos, W.P.; Batista, L.F.Z.; Naumann, S.; Wick, W.; Weller, M.; Menck, C.F.M.; Kaina, B. Apoptosis in malignant glioma cells triggered by the temozolomide-induced DNA lesion $O^{6}$-methylguanine. Oncogene 2007, 26, 186-197. [CrossRef]

19. Knizhnik, A.V.; Roos, W.P.; Nikolova, T.; Quiros, S.; Tomaszowski, K.H.; Christmann, M.; Kaina, B. Survival and death strategies in glioma cells: Autophagy, senescence and apoptosis triggered by a single type of temozolomide-induced DNA damage. PLoS ONE 2013, 8, e55665. [CrossRef]

20. Nikolova, T.; Marini, F.; Kaina, B. Genotoxicity testing: Comparison of the $\gamma \mathrm{H} 2 \mathrm{AX}$ focus assay with the alkaline and neutral comet assays. Mutat. Res. Gen. Tox. En. 2017, 822, 10-18. [CrossRef]

21. Khoury, I.; Zalko, D.; Audebert, M. Validation of the high-throughput genotoxicity assay screening using $\gamma \mathrm{H} 2 \mathrm{AX}$ in-cell western assay on HepG2 cells. Environ. Mol. Mutagen. 2013, 54,737-746. [CrossRef]

22. Wiewrodt, D.; Nagel, G.; Dreimuller, N.; Hundsberger, T.; Perneczky, A.; Kaina, B. MGMT in primary and recurrent human glioblastomas after radiation and chemotherapy and comparison with p53 status and clinical outcome. Int. J. Cancer 2008, 122, 1391-1399. [CrossRef] [PubMed]

23. Esteller, M.; Hamilton, S.R.; Burger, P.C.; Baylin, S.B.; Herman, J.G. Inactivation of the DNA repair gene O6-methylguanine-DNA methyltransferase by promoter hypermethylation is a common event in primary human neoplasia. Cancer Res. 1999, 59, 793-797.

24. Christmann, M.; Nagel, G.; Horn, S.; Krahn, U.; Wiewrodt, D.; Sommer, C.; Kaina, B. MGMT activity, promoter methylation and immunohistochemistry of pretreatment and recurrent malignant gliomas: A comparative study on astrocytoma and glioblastoma. Int. J. Cancer 2010, 127, 2106-2118. [CrossRef]

25. Esteller, M.; Garcia-Foncillas, J.; Andion, E.; Goodman, S.N.; Hidalgo, O.F.; Vanaclocha, V.; Baylin, S.B.; Herman, J.G. Inactivation of the DNA-repair gene MGMT and the clinical response of gliomas to alkylating agents. N. Engl. J. Med. 2000, 343, 1350-1354. [CrossRef] [PubMed]

26. Hegi, M.E.; Diserens, A.C.; Gorlia, T.; Hamou, M.F.; de Tribolet, N.; Weller, M.; Kros, J.M.; Hainfellner, J.A.; Mason, W.; Mariani, L.; et al. MGMT gene silencing and benefit from temozolomide in glioblastoma. N. Engl. J. Med. 2005, 352, 997-1003. [CrossRef] [PubMed]

27. Stupp, R.; Hegi, M.E.; Mason, W.P.; van den Bent, M.J.; Taphoorn, M.J.; Janzer, R.C.; Ludwin, S.K.; Allgeier, A.; Fisher, B.; Belanger, K.; et al. Effects of radiotherapy with concomitant and adjuvant temozolomide versus radiotherapy alone on survival in glioblastoma in a randomised phase iii study: 5-year analysis of the eortc-ncic trial. Lancet Oncol. 2009, 10, 459-466. [CrossRef]

28. Stepanenko, A.A.; Chekhonin, V.P. Recent advances in oncolytic virotherapy and immunotherapy for glioblastoma: A glimmer of hope in the search for an effective therapy? Cancers 2018, 10, 492. [CrossRef] 
29. Wick, W.; Steinbach, J.P.; Kuker, W.M.; Dichgans, J.; Bamberg, M.; Weller, M. One week on/one week off: A novel active regimen of temozolomide for recurrent glioblastoma. Neurology 2004, 62, 2113-2115. [CrossRef]

30. Strik, H.M.; Marosi, C.; Kaina, B.; Neyns, B. Temozolomide dosing regimens for glioma patients. Curr. Neurol. Neurosci. Rep. 2012, 12, 286-293. [CrossRef]

31. Stupp, R.; Mason, W.P.; van den Bent, M.J.; Weller, M.; Fisher, B.; Taphoorn, M.J.; Belanger, K.; Brandes, A.A.; Marosi, C.; Bogdahn, U.; et al. Radiotherapy plus concomitant and adjuvant temozolomide for glioblastoma. N. Engl. J. Med. 2005, 352, 987-996. [CrossRef] [PubMed]

32. Wick, W.; Winkler, F. Regimen of procarbazine, lomustine, and vincristine versus temozolomide for gliomas. Cancer 2018, 124, 2674-2676. [CrossRef] [PubMed]

33. Weller, M.; Steinbach, J.P.; Wick, W. Temozolomide: A milestone in the pharmacotherapy of brain tumors. Future Oncol. 2005, 1, 747-754. [CrossRef] [PubMed]

34. Batchelor, T. Temozolomide for malignant brain tumours. Lancet 2000, 355, 1115-1116. [CrossRef]

35. Danson, S.J.; Middleton, M.R. Temozolomide: A novel oral alkylating agent. Expert Rev. Anticancer Ther. 2001, 1, 13-19. [CrossRef] [PubMed]

36. Friedman, H.S.; Kerby, T.; Calvert, H. Temozolomide and treatment of malignant glioma. Clin. Cancer Res. 2000, 6, 2585-2597. [PubMed]

37. Marzolini, C.; Decosterd, L.A.; Shen, F.; Gander, M.; Leyvraz, S.; Bauer, J.; Buclin, T.; Biollaz, J.; Lejeune, F. Pharmacokinetics of temozolomide in association with fotemustine in malignant melanoma and malignant glioma patients: Comparison of oral, intravenous, and hepatic intra-arterial administration. Cancer Chemother. Pharmacol. 1998, 42, 433-440. [CrossRef] [PubMed]

38. Newlands, E.; Stevens, M.; Wedge, S.; Wheelhouse, R.; Brock, C. Temozolomide: A review of its discovery, chemical properties, pre-clinical development and clinical trials. Cancer Treat. Rev. 1997, 23, 35-61. [CrossRef]

39. Portnow, J.; Badie, B.; Chen, M.; Liu, A.; Blanchard, S.; Synold, T.W. The neuropharmacokinetics of temozolomide in patients with resectable brain tumors: Potential implications for the current approach to chemoradiation. Clin. Cancer Res. 2009, 15, 7092-7098. [CrossRef] [PubMed]

40. Ostermann, S.; Csajka, C.; Buclin, T.; Leyvraz, S.; Lejeune, F.; Decosterd, L.A.; Stupp, R. Plasma and cerebrospinal fluid population pharmacokinetics of temozolomide in malignant glioma patients. Clin. Cancer Res. 2004, 10, 3728-3736. [CrossRef]

41. Eich, M.; Roos, W.P.; Nikolova, T.; Kaina, B. Contribution of ATM and ATR to the resistance of glioblastoma and malignant melanoma cells to the methylating anticancer drug temozolomide. Mol. Cancer Ther. 2013, 12, 2529-2540. [CrossRef] [PubMed]

42. D’Orazi, G.; Cecchinelli, B.; Bruno, T.; Manni, I.; Higashimoto, Y.; Saito, S.; Gostissa, M.; Coen, S.; Marchetti, A.; Del Sal, G.; et al. Homeodomain-interacting protein kinase-2 phosphorylates p53 at ser 46 and mediates apoptosis. Nat. Cell Biol. 2002, 4, 11-19. [CrossRef] [PubMed]

43. Hofmann, T.G.; Moller, A.; Sirma, H.; Zentgraf, H.; Taya, Y.; Droge, W.; Will, H.; Schmitz, M.L. Regulation of p53 activity by its interaction with homeodomain-interacting protein kinase-2. Nat. Cell Biol. 2002, 4, 1-10. [CrossRef] [PubMed]

44. Winter, M.; Sombroek, D.; Dauth, I.; Moehlenbrink, J.; Scheuermann, K.; Crone, J.; Hofmann, T.G. Control of hipk2 stability by ubiquitin ligase Siah-1 and checkpoint kinases ATM and ATR. Nat. Cell Biol. 2008, 10, 812-824. [CrossRef] [PubMed]

45. Calzado, M.A.; de la Vega, L.; Munoz, E.; Schmitz, M.L. Autoregulatory control of the p53 response by Siah-1-mediated Hipk2 degradation. Biol. Chem. 2009, 390, 1079-1083. [CrossRef] [PubMed]

46. Muller, M.; Wilder, S.; Bannasch, D.; Israeli, D.; Lehlbach, K.; Li-Weber, M.; Friedman, S.L.; Galle, P.R.; Stremmel, W.; Oren, M.; et al. p53 activates the CD95 (Apo-1/Fas) gene in response to DNA damage by anticancer drugs. J. Exp. Med. 1998, 188, 2033-2045. [CrossRef]

47. Hermisson, M.; Klumpp, A.; Wick, W.; Wischhusen, J.; Nagel, G.; Roos, W.; Kaina, B.; Weller, M. O6-methylguanine DNA methyltransferase and p53 status predict temozolomide sensitivity in human malignant glioma cells. J. Neurochem. 2006, 96, 766-776. [CrossRef]

48. Mihara, M.; Erster, S.; Zaika, A.; Petrenko, O.; Chittenden, T.; Pancoska, P.; Moll, U.M. p53 has a direct apoptogenic role at the mitochondria. Mol. Cell 2003, 11, 577-590. [CrossRef] 
49. Chipuk, J.E.; Kuwana, T.; Bouchier-Hayes, L.; Droin, N.M.; Newmeyer, D.D.; Schuler, M.; Green, D.R. Direct activation of bax by p53 mediates mitochondrial membrane permeabilization and apoptosis. Science 2004, 303, 1010-1014. [CrossRef] [PubMed]

50. Christmann, M.; Boisseau, C.; Kitzinger, R.; Berac, C.; Allmann, S.; Sommer, T.; Aasland, D.; Kaina, B.; Tomicic, M.T. Adaptive upregulation of DNA repair genes following benzo(a)pyrene diol epoxide protects against cell death at the expense of mutations. Nucleic Acids Res. 2016, 44, 10727-10743. [CrossRef]

51. Thomas, A.D.; Fahrer, J.; Johnson, G.E.; Kaina, B. Theoretical considerations for thresholds in chemical carcinogenesis. Mutat. Res. Rev. Mutat. Res. 2015, 765, 56-67. [CrossRef] [PubMed]

52. Kaina, B.; Ochs, K.; Grosch, S.; Fritz, G.; Lips, J.; Tomicic, M.; Dunkern, T.; Christmann, M. BER, MGMT, and MMR in defense against alkylation-induced genotoxicity and apoptosis. Prog. Nucleic Acid Res. Mol. Biol. 2001, 68, 41-54. [PubMed]

53. Fritz, G.; Tano, K.; Mitra, S.; Kaina, B. Inducibility of the DNA repair gene encoding $O^{6}$-methylguanine-DNA methyltransferase in mammalian cells by DNA-damaging treatments. Mol. Cell. Biol. 1991, 11, 4660-4668. [CrossRef] [PubMed]

54. Rafferty, J.A.; Clarke, A.R.; Sellappan, D.; Koref, M.S.; Frayling, I.M.; Margison, G.P. Induction of murine O6-alkylguanine-DNA-alkyltransferase in response to ionising radiation is p53 gene dose dependent. Oncogene 1996, 12, 693-697. [PubMed]

55. Bayer, N.; Schober, D.; Prchla, E.; Murphy, R.F.; Blaas, D.; Fuchs, R. Effect of bafilomycin A1 and nocodazole on endocytic transport in HeLa cells: Implications for viral uncoating and infection. J. Virol. 1998, 72, 9645-9655. [PubMed]

(C) 2019 by the authors. Licensee MDPI, Basel, Switzerland. This article is an open access article distributed under the terms and conditions of the Creative Commons Attribution (CC BY) license (http://creativecommons.org/licenses/by/4.0/). 